Check for updates

Cite this: RSC Adv., 2019, 9, 18565

\title{
Zwitterionic superabsorbent polymer hydrogels for efficient and selective removal of organic dyes $\uparrow$
}

\author{
Tanzil Ur Rehman, Luqman Ali Shah, (D)* Mansoor Khan, Muhammad Irfan \\ and Noor Saeed Khattak
}

A novel zwitterionic superabsorbent polymer hydrogel [ZI-SAH] was synthesized by free radical polymerization and used for the removal of crystal violet (CV) and congo red (CR) from an aqueous medium. $\mathrm{ZI}$-SAH was composed of $\mathrm{pH}$-sensitive monomers poly(3-acrylamidopropyl) trimethylammoniumchloride (APTMACl) and 2-acrylamido-2-methylpropanesulphonic acid (AAMPSA). The hydrogel was characterized by SEM and FT-IR spectroscopy, while the visco-elastic behavior was studied using rheological tests. The hydrogel showed a point of zero charge (PZC) at pH 7.2 and high swelling abilities of $3715 \%$ at $\mathrm{pH} 9$ and $3112 \%$ at $\mathrm{pH}$ 5. The cationic crystal violet (CV) and anionic congo red (CR) dyes were employed to investigate the removal ability of $\mathrm{ZI}$-SAH using the batch adsorption method. The materials became more selective towards oppositely charged dyes at $\mathrm{pH} 5$ and 9. The effects of parameters such as contact time, initial concentration of dyes, $\mathrm{pH}, \mathrm{ZI}-\mathrm{SAH}$ dosage and ionic strength on the removal performance were investigated. A kinetic study was carried out via Lagergren pseudo first order and pseudo second order kinetics. The adsorption efficiencies of Zl-SAH were $13.6 \mathrm{mg} \mathrm{g}^{-1}$ for $\mathrm{CV}$ and $9.07 \mathrm{mg} \mathrm{g}^{-1}$ for $\mathrm{CR}$ with \% removal values of 97 and 89 , respectively. The thermodynamic parameters, namely, $\Delta G^{\circ}, \Delta H^{\circ}$ and $\Delta S^{\circ}$ were determined, and the negative value of free energy showed that the process of adsorption was spontaneous. $\mathrm{ZI}-\mathrm{SAH}$ was recycled and reused in five consecutive cycles with removal efficiency $>75 \%$.

Received 2nd April 2019

Accepted 23rd May 2019

DOI: $10.1039 / c 9 r a 02488 c$

rsc.li/rsc-advances

\section{Introduction}

To overcome the issues caused by water pollution is a prominent research area within the scientific community nowadays. After the industrial revolution, the industrial and manufacturing processes increased and the waste water from these industries directly affected the flora and fauna of water ecosystems. Many major and minor causes of water pollution were studied by researchers, and one of the most significant causes is the release of organic dyes (macromolecules) from textile industries. ${ }^{1}$ In addition, the industries of food processing, ${ }^{2}$ pharmaceuticals, ${ }^{3}$ and leather ${ }^{4}$ are the major contributors of organic dye effluents, which are directly released into water and cause water pollution. The toxicity of organic dyes and heavy metals as pollutants in water has been reported in many studies. $^{5}$

The treatment of industrial waste water having organic pollutants is a challenging process and phenomenon for researchers. Several traditional approaches such as Fenton reactions have been used for organic pollutant degradation. ${ }^{6}$

Polymer Laboratory, National Center of Excellence in Physical Chemistry, University of Peshawar, Peshawar, KPK 25120, Pakistan. E-mail: Luqman_alisha@yahoo.com; luqman_alisha@uop.edu.pk; Fax: +92-91-9216671; Tel: +92-91-9216766

$\dagger$ Electronic supplementary information (ESI) available. See DOI: $10.1039 / \mathrm{c} 9 \mathrm{ra} 02488 \mathrm{c}$
Naturally, it is not possible to directly degrade and remove the waste water organic pollutants, especially the organic dyes. ${ }^{7}$

Although the use of dyes for various industrial purposes cannot be denied due to their applications. Their harmful effects, especially on the environment, are more severe as they are more detrimental in general, in particular to the aquatic system. Water toxicity can directly impact living organisms, particularly human beings. It causes many biological and physiological problems in human beings such as cancer as well as lung, kidney and skin problems.

Many techniques have been used by various laboratories, industries and researchers for waste water treatment and these include physical treatments, chemical processes and biological activities. These techniques include both classical as well as modern techniques such as degradation, ${ }^{8,9}$ ion exchange, ${ }^{10}$ coagulation, ${ }^{11}$ oxidation, photo catalysis ${ }^{12-14}$ and adsorption. ${ }^{15,16}$ Thus, for the present work, the adsorption technique was selected due to its reasonably greater effectivity and easy access. ${ }^{17}$

Mostly, in the application of novel absorbents, researchers take more interest in the synthesis of superabsorbent hydrogels (SAH) and their applications for protecting water bodies from toxic dyes and heavy metals. ${ }^{18,19}$ Hydrogels can be used due to their easy synthesis and handling, low $\operatorname{cost}^{20}$ and excellent absorbance capacity. $^{21}$ Systematically speaking, hydrogels 
comprise 3-dimensional networks ${ }^{22}$ with excellent elasticity and better affinity towards water absorption. ${ }^{23,24}$ The absorption and swelling property of a hydrogel is due to the hydrophilic part in the backbone, which shows greater affinity towards water. ${ }^{25}$ This hydrophilic (functional group) part consists of hydroxyl $(-\mathrm{OH})$, amine $\left(-\mathrm{NH}_{2}\right)$, sulphonic $\left(-\mathrm{SO}_{3} \mathrm{H}\right)$, carboxyl $(-\mathrm{COOH})$, and amide $\left(-\mathrm{CONH}_{2}\right)$ groups, which make the gels attractive to charged organic pollutants and heavy metals via encapsulation phenomena. $^{26}$

In the present work, a novel zwitterionic superabsorbent hydrogel (ZI-SAH) copolymer was synthesized by the free radical co-polymerization of $\mathrm{pH}$-sensitive cationic 3-acrylamidopropyl trimethylammoniumchloride (APTMACl) and anionic 2acrylamido-2-methylpropanesulphonic acid (AAMPSA) monomers. The rheological property and swelling ability were studied in detail. ZI-SAH was applied successfully for the removal of cationic (crystal violet, CV) and anionic (congo red, CR) dyes in an aqueous medium. ZI-SAH was found to be more selective and efficient at pH 5 and 9 for $\mathrm{CR}$ and CV, respectively. The materials were recycled and reused for five consecutive cycles during the removal process, and the efficiency was still above $75 \%$.

\section{Experimental}

\subsection{Materials}

3-Acrylamidopropyltrimethyl ammonium chloride (APTMACl, Sigma Aldrich, 75 wt\%) and 2-acrylamido-2methylpropanesulphonic acid (AAMPSA, 98\%, Alfa Aesar) were used as cationic monomer and anionic monomer, respectively. $N, N^{\prime}$-Methylenebisacrylamide (MBA, 99\%, Sigma Aldrich) was used as a cross-linker, and ammonium persulfate (APS 98\%, Sigma Aldrich) was used as an initiator. These chemicals were directly used for synthesizing hydrogels. Congo red (CR, Sigma Aldrich) and crystal violet (CV, Sigma Aldrich) as sources of organic dyes were used as-received. Milli-Q distilled water was used throughout the experimental work. $\mathrm{NaNO}_{3}$ (Merck), $\mathrm{NaOH}$ $(\mathrm{BDH}), \mathrm{HCl}$ (Sigma), and $\mathrm{KCl}(\mathrm{BDH})$ were used as reagents during the research work.

\subsection{Synthesis of zwitterionic superabsorbent hydrogels (ZI- SAH)}

ZI-SAH was synthesized using the free radical copolymerization process at $60^{\circ} \mathrm{C}$ for 30 minutes in an oven. AAMPSA (0.98 g) and APTMACl $(120 \mu \mathrm{l})$ were taken and placed in a vial, which contained $5 \mathrm{ml}$ of Milli-Q water and $0.05 \mathrm{~g}$ of MBA as a cross-linker. The mixture was sonicated and vortexed till a homogeneous mixture was obtained. Finally, the mixture was charged with APS $\left(0.05 \mathrm{~g} / 2 \mathrm{ml}\right.$ of $\left.\mathrm{H}_{2} \mathrm{O}\right)$ and kept in an oven at $60{ }^{\circ} \mathrm{C}$ for 30 minutes. The synthesized product was washed with water to remove the unreacted monomers and other substances, dried in a vacuum oven at $40{ }^{\circ} \mathrm{C}$ and $0.75 \mathrm{kPa}$ and stored for further use.

\subsection{Dye removal study using ZI-SAH}

The hydrogel was employed to remove CV and CR dyes in batch absorption experiments. For each test, a small piece $(0.01 \mathrm{~g})$ of ZI-SAH was added to $20 \mathrm{ml}$ solution of $\mathrm{CV}$ and $\mathrm{CR}$. The $\mathrm{pH}$ was adjusted and recorded using a $\mathrm{pH}$ meter $(\mathrm{pH}-2601)$ and it was shaken at $150 \mathrm{rpm}$ for $14 \mathrm{~h}$ (equilibrium time) in a $\mathrm{SH}-30 \mathrm{Lab}$ Shaker. For the maximum removal of $\mathrm{CV}$ and $\mathrm{CR}$, the $\mathrm{pH}$ values of the solutions were maintained at 9 and 5 for $\mathrm{CV}$ and CR, respectively. UV/Vis spectroscopy (UV-2100) was used to monitor the absorbance of the $\mathrm{CV}$ and CR dyes in the solution during their removal process from water by the adsorbent. The $\lambda_{\max }$ values of CV and CR were obtained and matched with the previously reported values of $497 \mathrm{~nm}$ for CR and $588 \mathrm{~nm}$ for CV. The capacity for the absorption of the hydrogels for dye equilibrium concentration $\left(C_{\mathrm{e}}\right)$ was calculated and analyzed. The gels were separated from the solution by centrifugation at $5000 \mathrm{rpm}$ for 15 minutes and then filtered via Whatman-42 filter papers. All the specific conditions of the experiment are given in the caption of each figure.

\section{Results and discussion}

\subsection{Characterization of ZI-SAH}

Poly(3-acrylamidopropyl)-trimethylammoniumchloride-co-2acrylamido-2-methylpropanesulphonic acid, i.e., ZI-SAH copolymer gels were prepared using free-radical polymerization in the presence of BIS as a cross-linker and APS as an initiator. All the FTIR spectra were recorded on PerkinElmer spectrum version 10.5.1. The FTIR spectra for ZI-SAH and individual cationic (C-SAH) and anionic (A-SAH) hydrogels are given in Fig. 1a. All the associated transmittance peaks corresponding to the functional groups present in copolymer hydrogels were observed. The peak at $1645 \mathrm{~cm}^{-1}$ is due to the carbonyl group (amide), and the peak at $1555 \mathrm{~cm}^{-1}$ is assigned to the bending vibration of the -NH group; the sharp peaks at 1145 and $1045 \mathrm{~cm}^{-1}$ are because of the bending and stretching vibrations of the $\mathrm{S}=\mathrm{O}$ (sulphonic) group, respectively. The peak at $3296 \mathrm{~cm}^{-1}$ is attributed to the stretching vibration of amide $(-\mathrm{CONH})$ groups present in the synthesized hydrogel, and the peak at $2936 \mathrm{~cm}^{-1}$ corresponds to the asymmetric stretching vibration of $\mathrm{C}-\mathrm{H}$. Similarly, the peaks at $600 \mathrm{~cm}^{-1}$ and $500 \mathrm{~cm}^{-1}$ are attributed to the $-\mathrm{OH}$ group's out-of-plane bending. The formation of ZI-SAH was confirmed by the disappearance of the peaks at 2477 and $2714 \mathrm{~cm}^{-1}$ in the case of pure anionic hydrogels and the disappearance of the peaks at 3393, 1099, and $959 \mathrm{~cm}^{-1}$ in the case of cationic hydrogels. Similarly, the appearance of new peaks at $3070 \mathrm{~cm}^{-1}$ for the ZI-SAH copolymer indicated the interaction between anionic and cationic monomers and the formation of the ZI-SAH copolymer. The surface morphology of ZI-SAH was further elaborated by scanning electron microscopy, as shown in Fig. 1b, which indicates that the surface is rough and most suitable for the adsorption process.

\subsection{Characterization of ZI-SAH after dye entrapment}

The removal capacity of ZI-SAH towards anionic (congo red, CR) and cationic (crystal violet, CV) dyes was examined in an aqueous medium. The sorption of dyes was visually confirmed by changing the solution color, as shown in Fig. 2a. As APTMACl is cationic and AAMPSA is anionic, both undergo structural 

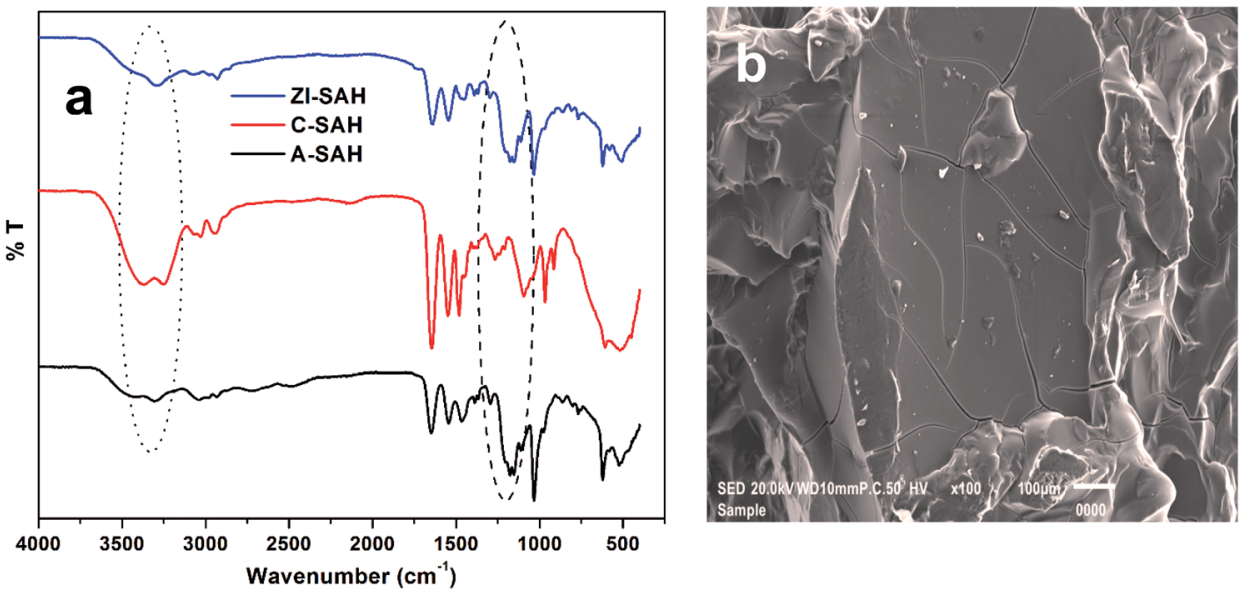

Fig. 1 (a) FTIR spectra of the superabsorbent hydrogel and (b) SEM image of ZI-SAH.

changes with the change in the $\mathrm{pH}$ of the medium. The trapping and removal of the dyes by ZI-SAH are due to the diffusion and electrostatic forces of attraction. The existence of positive charge on the polymer network favors the attraction of anionic dyes, while the negative charge attracts cationic dyes. Above and below the point of zero charge (PZC), ZI-SAH became more selective and removed the oppositely charged dye more efficiently. After absorption, the hydrogels were characterized by FTIR spectra, as shown in Fig. 2b. The peaks at 1203 and $1391 \mathrm{~cm}^{-1}$ are the characteristic peaks for $\mathrm{CV}$, and the peak at $1441 \mathrm{~cm}^{-1}$ is assigned to the $\mathrm{C}=\mathrm{C}$ aromatic group; the peak at $1540 \mathrm{~cm}^{-1}$ is probably due to the $\mathrm{N}=\mathrm{N}$ stretching band of the
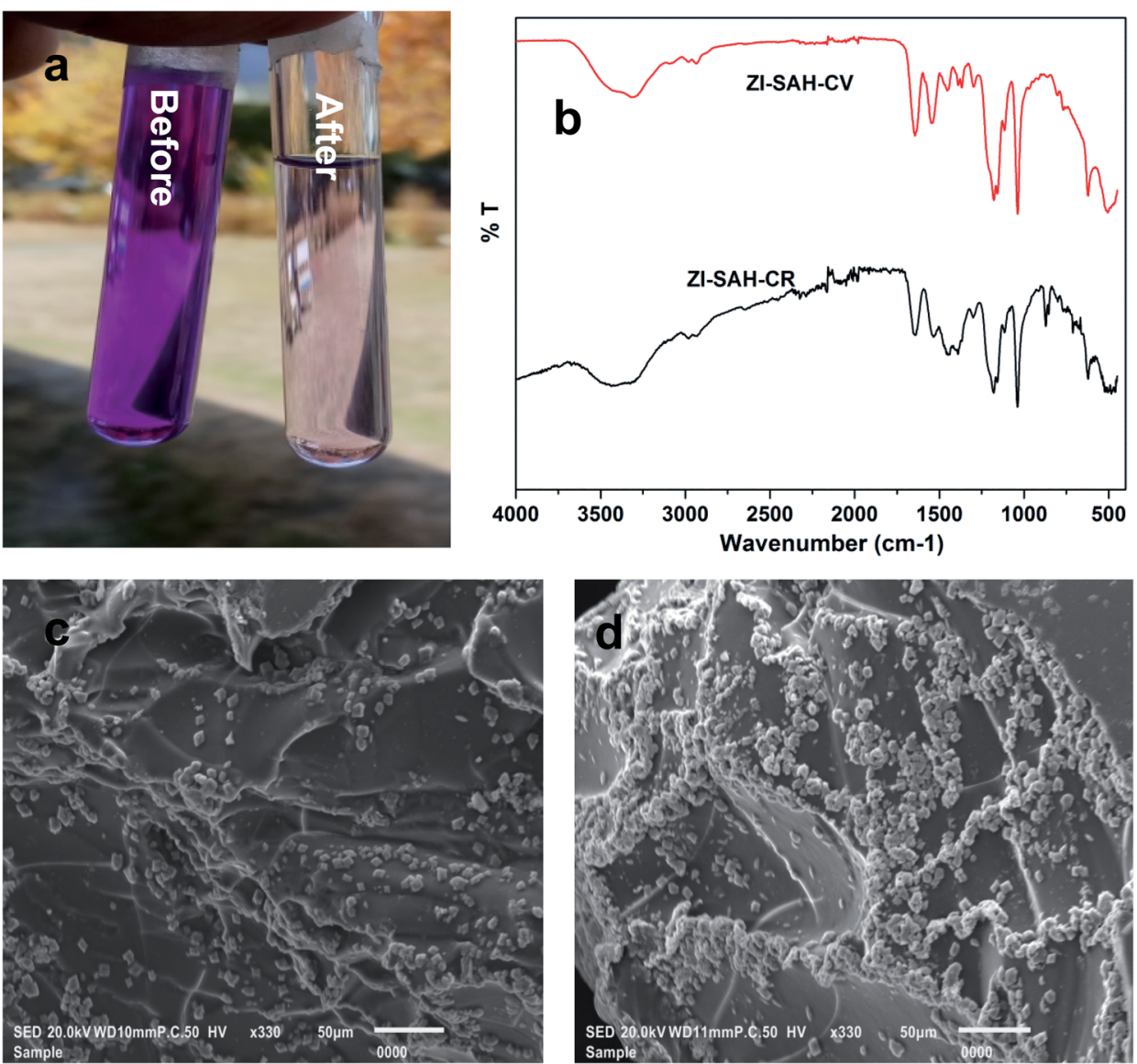

Fig. 2 (a) Discoloration of CV solution before and after adsorption; (b) FTIR spectra; (c) SEM image of ZI-SAH-CV and (d) SEM image of ZI-SAHCR. 

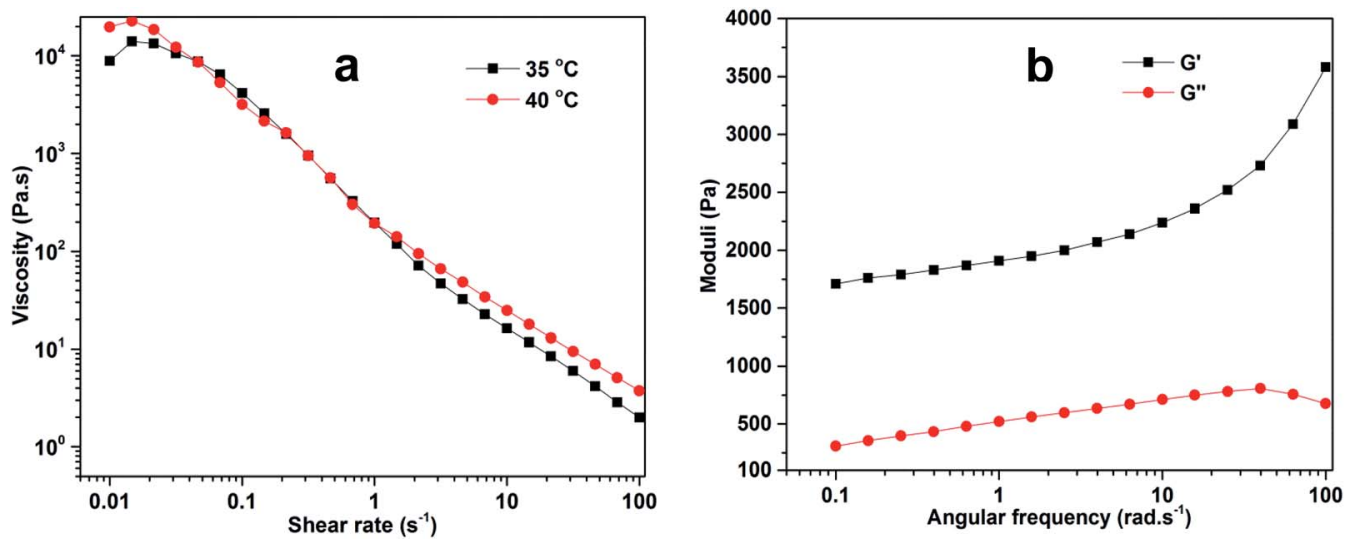

Fig. 3 Rheological investigation of (a) viscosity as a function of shear rate and (b) moduli as a function of angular frequency for $\mathrm{ZI}-\mathrm{SAH}$ at $40{ }^{\circ} \mathrm{C}$.

azo group in CR. The change in surface morphology was also studied by SEM, as shown in Fig. 2(c and d), which indicated and confirmed the attachment of dyes in aggregates on the surface of ZI-SAH successfully.

\subsection{Rheological study of ZI-SAH}

Rheology is the study of the flow behavior of a liquid and soft solid having a non-Newtonian property under the application of force. Currently, rheology is a characterizing tool used to verify the deformation and mechanical properties of polymers, emulsions, hydrogels, etc. Various characterization techniques have been used to determine the internal properties such as physical and chemical cross-linking and visco-elastic behavior as well as the internal structure using rheology. The rheological study of hydrogels helps understand the mechanical strength of a copolymer hydrogel while using rheological parameters such as the relationship between viscosity $(\eta)$ and shear rate $(\tau)$, shear stress vs. shear rate, and moduli (storage modulus $\left(G^{\prime}\right)$, the property of elastic materials and loss modulus $\left(\mathrm{G}^{\prime \prime}\right)$, and the property of viscous materials) via frequency and oscillatory dynamic mechanical analysis. ${ }^{27}$ Thus, rheological modeling enables researchers to differentiate between the viscous and elastic responses ${ }^{28}$ of the materials to be studied.

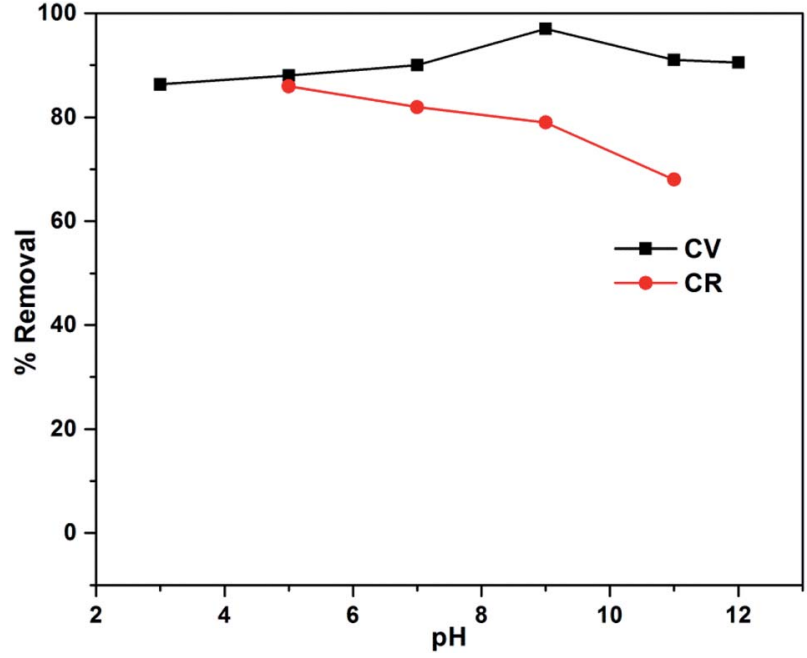

Fig. $5 \%$ Removal as a function of $\mathrm{pH}$ for $\mathrm{ZI}-\mathrm{SAH}$.

3.3.1. Flow curve study. Viscosity measurements as a function of shear rate were obtained at $35^{\circ} \mathrm{C}$ and $40{ }^{\circ} \mathrm{C}$, as shown in Fig. 3a. A slight increase in viscosity was observed initially, followed by a decreasing trend with the increase in the shear
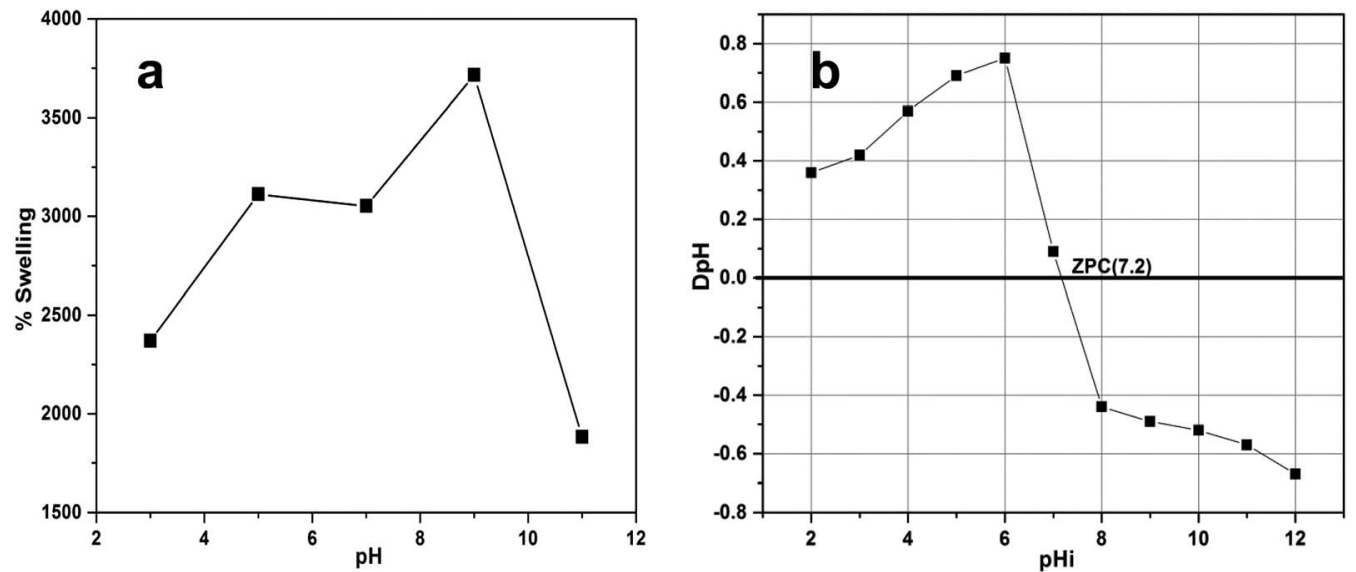

Fig. 4 (a) \% swelling as a function of $\mathrm{pH}$ for $\mathrm{ZI}-\mathrm{SAH}$; temperature is $25^{\circ} \mathrm{C}$, dose is $0.90 \mathrm{~g} \pm 0.05$, equilibrium time is $24 \mathrm{~h}$. (b) Illustration of PZC of $\mathrm{ZI}-\mathrm{SAH}$; dose is $0.02 \mathrm{~g}, \mathrm{pH}$ range is $2-11$ using $0.1 \mathrm{~N} \mathrm{NaNO}_{3}$ solution, equilibrium time is $24 \mathrm{~h}$, and the volume taken is $20 \mathrm{ml}$. 

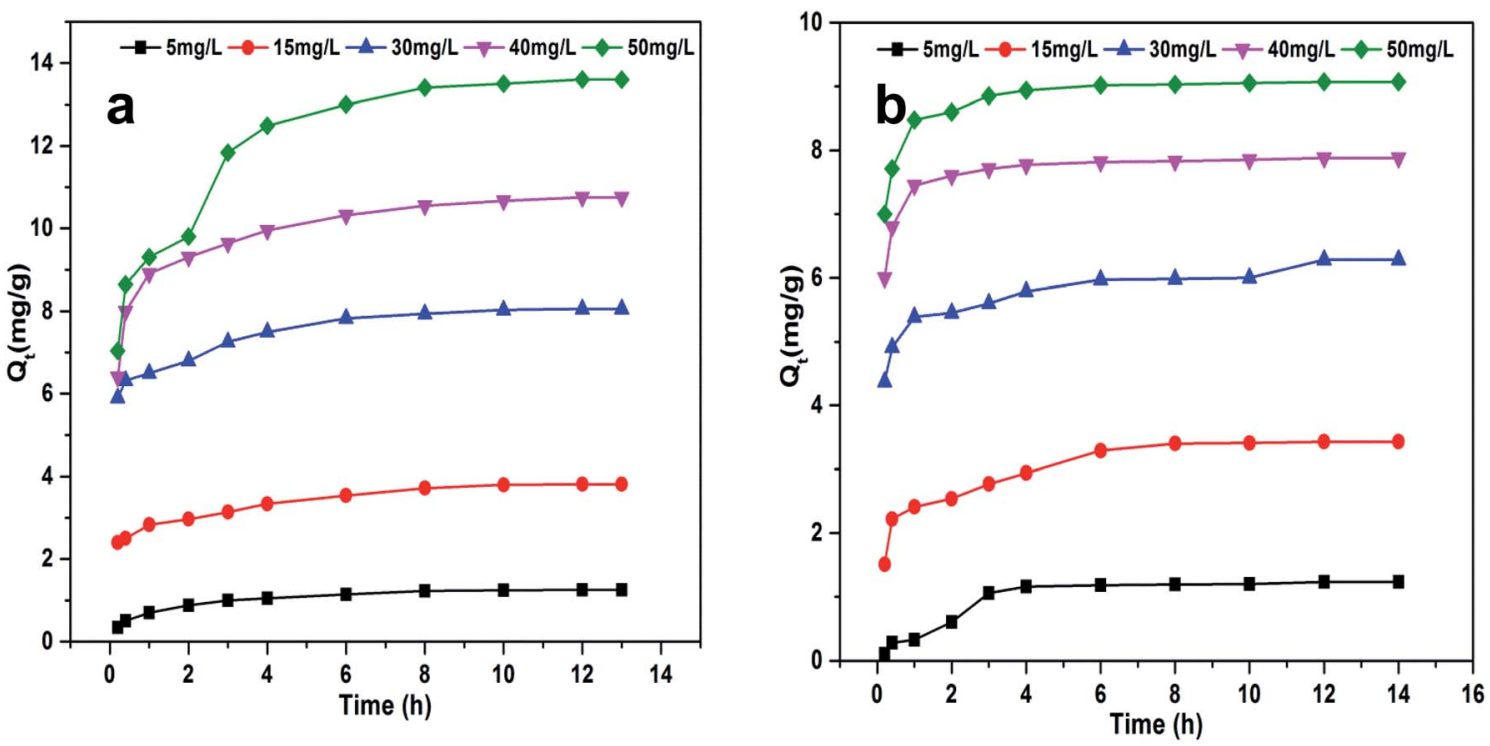

Fig. $6 Q_{\mathrm{t}}$ as a function of contact time at different initial concentrations of dyes: (a) $\mathrm{CV}$ at $\mathrm{pH} 9$ and (b) $\mathrm{CR}$ at $\mathrm{pH} 5$. ZI-SAH dose: $0.07 \mathrm{~g}$, temperature: $25^{\circ} \mathrm{C}$.

Table 1 Absorption capacity and \% removal of ZI-SAH towards CV and $\mathrm{CR}$ at different initial concentrations

\begin{tabular}{|c|c|c|c|c|}
\hline \multirow{2}{*}{$\begin{array}{l}\text { Initial concentration } \\
\text { (ppm) }\end{array}$} & \multicolumn{2}{|c|}{$q_{\mathrm{e}}\left(\mathrm{mg} \mathrm{g}^{-1}\right)$} & \multicolumn{2}{|c|}{ \% Removal } \\
\hline & CV & CR & $\mathrm{CV}$ & CR \\
\hline 5 & 1.25 & 1.23 & 98 & 86 \\
\hline 15 & 3.80 & 3.43 & 96 & 80 \\
\hline 30 & 8.06 & 6.28 & 95 & 73 \\
\hline 40 & 10.75 & 7.88 & 94 & 71 \\
\hline 50 & 13.6 & 9.07 & 92 & 70 \\
\hline
\end{tabular}

rate probably due to the deformation of intermolecular forces in the gels. These results showed that physical interactions, such as hydrogen bonds, existing in the polymer network are in the direction of the shear rate or flow, thus confirming a pseudoplastic behavior. ${ }^{29}$ It was further studied that the decrease in viscosity was less at a high temperature because the gels changed from a swollen to a collapsed semi-solid state while expelling water molecules from the three-dimensional network of the ZI-SAH system. ${ }^{30}$

3.3.2. Frequency sweep study. During frequency sweep, the loss modulus $\left(G^{\prime \prime}\right)$ and storage modulus $\left(G^{\prime}\right)$ as a function of angular frequency were measured, as shown in Fig. 3b. This study was carried out to justify the mechanical characteristics, which were more supportive during the elucidation of the threedimensional network of the gel, and this was necessary for studying the future application of these materials. The results indicate that the values of $G^{\prime}$ were greater than those of $G^{\prime \prime}$ for
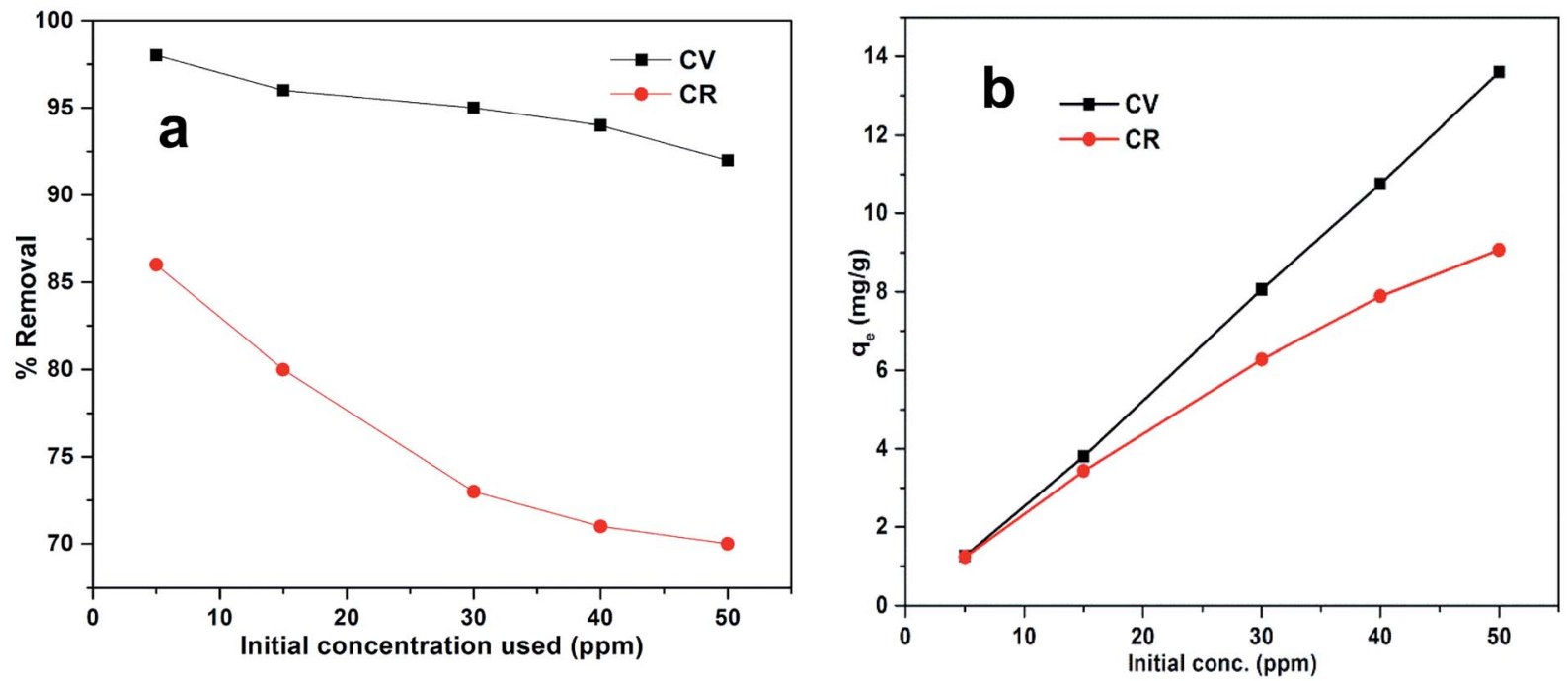

Fig. 7 (a) \% removal and (b) $q_{\mathrm{e}}\left(\mathrm{mg} \mathrm{g}^{-1}\right)$ as a function of initial concentration of dyes used for absorption process. $\mathrm{pH}$ for $\mathrm{CR}$ was 5 and that for $\mathrm{CV}$ was 9; equilibrium time was $14 \mathrm{~h}$. 


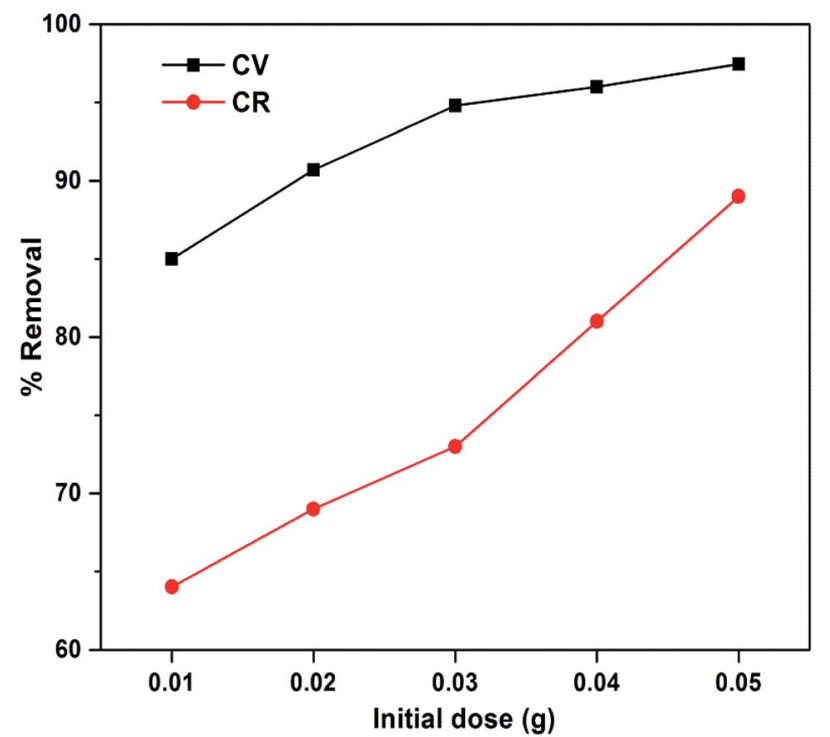

Fig. $8 \%$ Removal as a function of ZI-SAH dose at $25{ }^{\circ} \mathrm{C}$ with $14 \mathrm{~h}$ contact time; for $\mathrm{CV}$ : concentration $10 \mathrm{mg} \mathrm{L}^{-1}, \mathrm{pH} 9$ and for $\mathrm{CR}$ : concentration $15 \mathrm{mg} \mathrm{L}^{-1}, \mathrm{pH} 5$.

the entire range of angular frequency, illustrating that the elastic property is superior to the viscous property of the synthesized ZI-SAH. This phenomenon of the elastic property elaborated the concept of solid-like materials of the synthetic product, which is better for mechanical stability and applicable for the adsorption process. These results confirm that ZI-SAH can be used for the removal of dyes from solutions.

\subsection{Swelling property and point of zero charge (PZC)} measurement

The swelling property is one of the characteristics of gel materials. A dried gel swells due to the presence of ionic groups as well as due to the hydrophilicity and diffusion of water

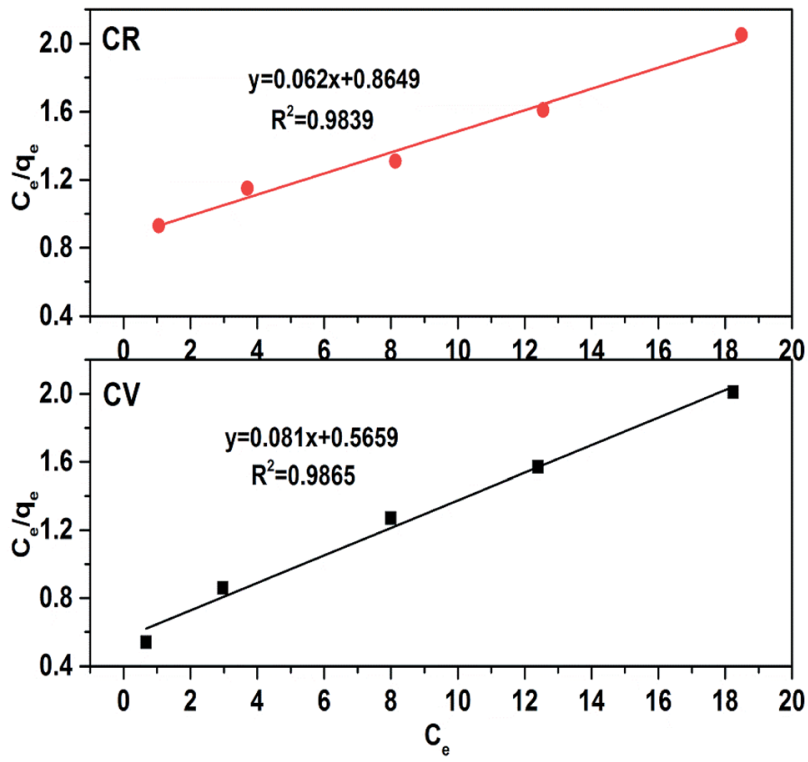

Fig. 10 Langmuir adsorption isotherm for dye removal in an aqueous medium using $\mathrm{ZI}-\mathrm{SAH}$.

molecules inside the network of the gel, which change it into a swollen state. Thus, the swelling of a gel in water justifies the concept of swelling ratio, which is actually the absorption of water by a dry gel. The swelling property of ZI-SAH was investigated at $\mathrm{pH} 3,5,7,9$ and 11 . Initially, it was found that at any $\mathrm{pH}$, the gel swelled at a considerable rate and then, the process slowed down; however, ZI-SAH was kept for $24 \mathrm{~h}$ until equilibrium was established between water and hydrogels. The maximum amount of swelling was found at pH 9 (3715\%) as well as at pH $5(3112 \%)$ compared to the dry weight, as shown in Fig. 4a. This was due to the presence of ionizing groups $\left(-\mathrm{N}^{+}\left(\mathrm{CH}_{3}\right)_{3}\right.$ and $\left.-\mathrm{SO}_{3} \mathrm{H}\right)$, which caused electrostatic repulsions in the 3D network of ZI-SAH and enhanced the hydrophilic nature of polymer chains. Thus, the water molecules easily
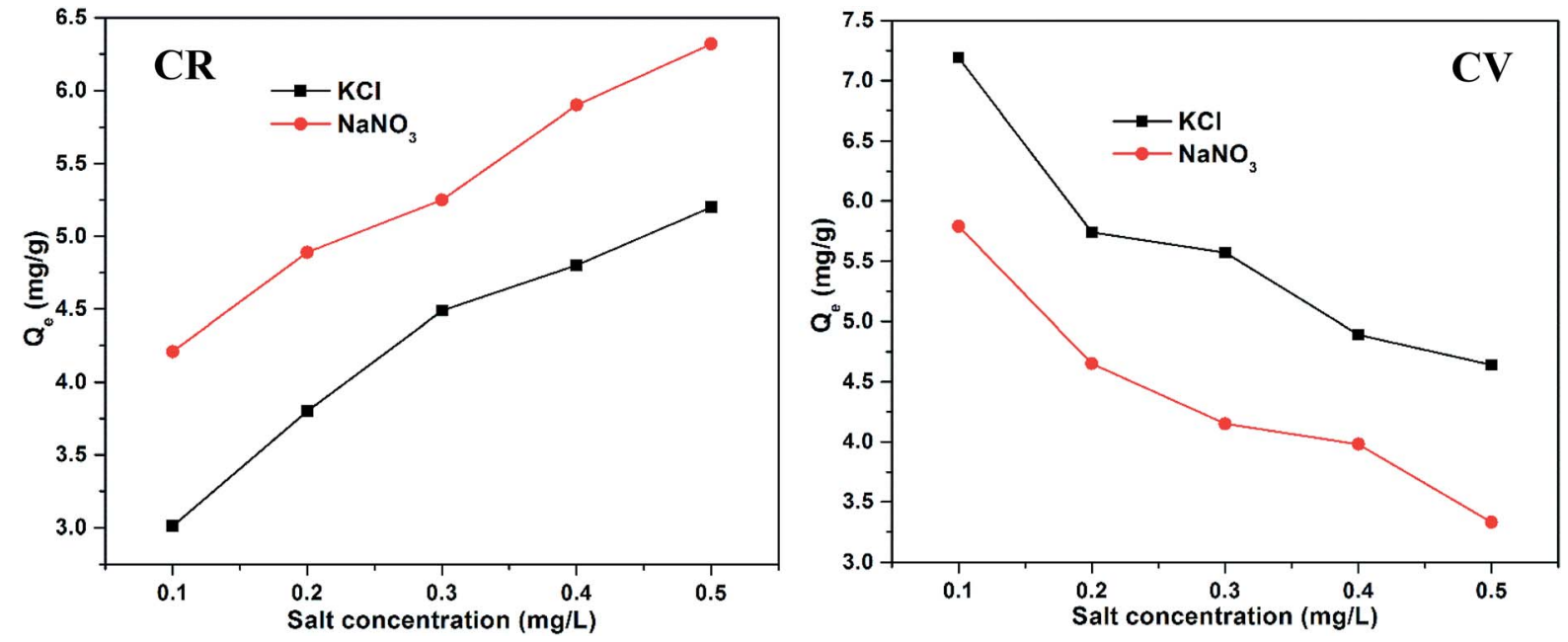

Fig. $9 Q_{e}$ as a function of different salt concentrations. ZI-SAH dose $0.02 \mathrm{~g}$; solution concentration of CV $20 \mathrm{mg} \mathrm{L}^{-1}$ and that of CR $50 \mathrm{mg} \mathrm{L}$; temperature $25^{\circ} \mathrm{C}$. 
Table 2 Various parameters obtained with different applied adsorption isotherms

\begin{tabular}{|c|c|c|c|c|c|c|c|c|c|c|c|c|}
\hline Dyes & \multicolumn{5}{|l|}{ Langmuir } & \multicolumn{4}{|c|}{ Freundlich } & \multicolumn{3}{|l|}{ Temkin } \\
\hline CR & 0.016 & 16.12 & 9.07 & 0.9839 & 0.218 & 1.147 & 1.32 & 0.753 & 0.9837 & 5.002 & 1106.05 & 0.9493 \\
\hline
\end{tabular}

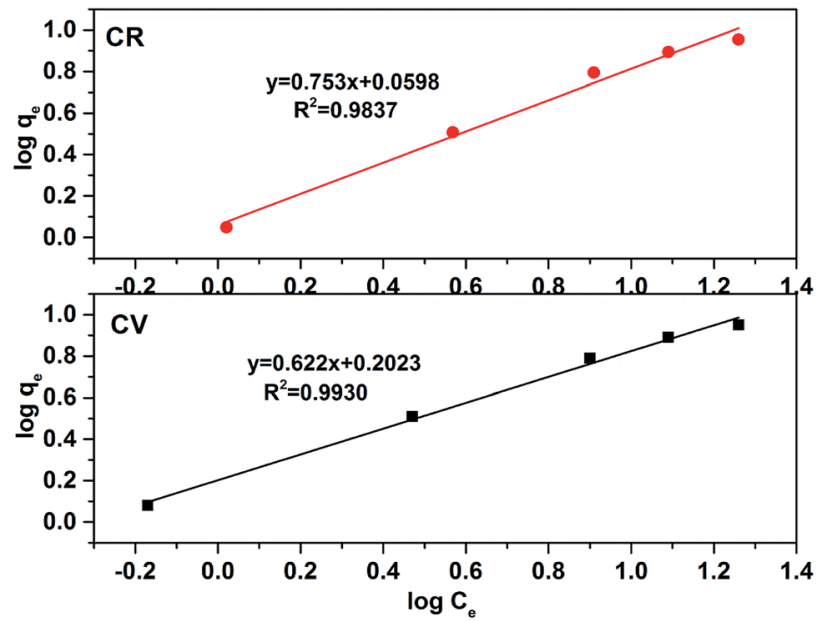

Fig. 11 Freundlich adsorption isotherm for dye removal in an aqueous medium using $\mathrm{ZI}-\mathrm{SAH}$

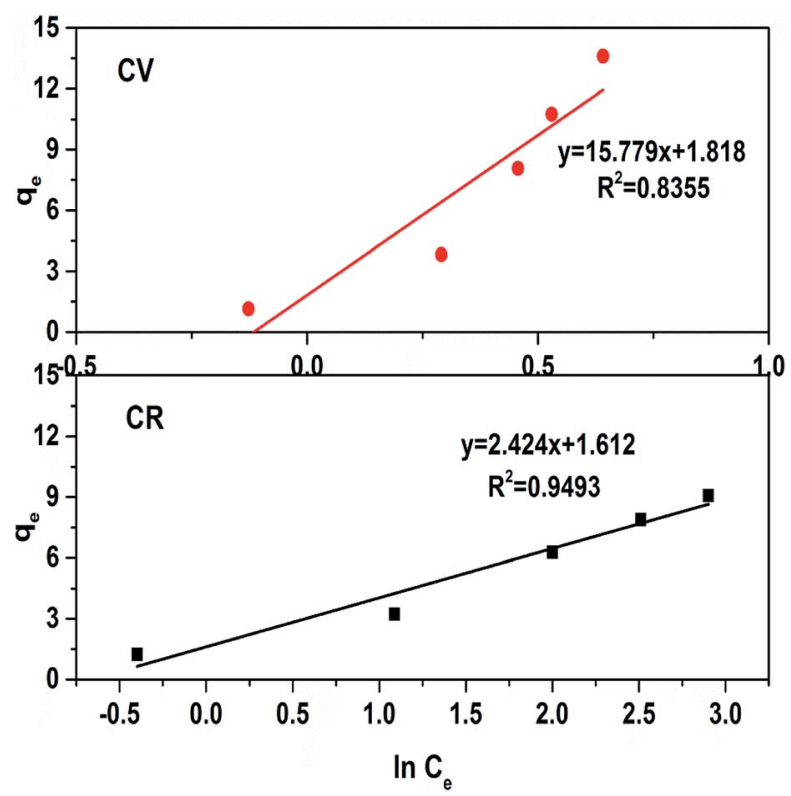

Fig. 12 Temkin adsorption isotherm for dye removal in an aqueous medium using $\mathrm{ZI}-\mathrm{SAH}$.

penetrated the polymer gel network to swell it. Thus, at $\mathrm{pH} 5$, the cationic part became more active and exhibited a greater number of positively charged repulsive sites. Moreover, at pH 9 , the anionic sites became more negatively charged, which extended the gel network to become larger in size. The high \% swelling at $\mathrm{pH} 9$ compared to that at $\mathrm{pH} 5$ is because of the compositional difference ( $85 \%: 10 \%$, \% mole composition) between the anionic and cationic monomers in ZI-SAH. The compositional difference was calculated through the number of moles of the individual monomer in the total composition of the ZI-SAH copolymer before the synthesis of ZI-SAH. The percent (\%) swelling was calculated by applying eqn (1):

$$
\% \text { Swelling }=\frac{W_{\mathrm{s}}-W_{\mathrm{d}}}{W_{\mathrm{d}}} \times 100
$$

Here, $W_{\mathrm{s}}$ and $W_{\mathrm{d}}$ are the swollen and dry weights of the ZI-SAH samples, respectively.

The swelling of ZI-SAH depends on the $\mathrm{pH}$ of the medium; therefore, the swelling was studied at different $\mathrm{pH}$ values in correlation with PZC (Fig. 4b). It was found that ZI-SAH swelled at all $\mathrm{pH}$ values due to the diffusion and synergistic effects of the cationic and anionic segments (electrostatic interactions). However, the swelling at PZC was only due to the diffusion process of water from the surrounding to the polymer network, while there was no contribution of the electrostatic repulsion of the $-\mathrm{N}^{+}\left(\mathrm{CH}_{3}\right)_{3}$ and $-\mathrm{SO}_{3} \mathrm{H}$ groups for swelling as the network exhibited net zero charge.

Point of zero charge (PZC) is the $\mathrm{pH}$ at which the surface of the adsorbent or material becomes neutral. PZC is very useful and helpful to know the behavior of adsorbents during the adsorption study. PZC of the ZI-SAH copolymer was examined and determined by adding $0.02 \mathrm{~g}$ of dried ZI-SAH into a number of sample bottles having $20 \mathrm{ml}$ of $0.01 \mathrm{M} \mathrm{NaNO}_{3}$ solution. Initially, the $\mathrm{pH}$ of each bottle was adjusted to $2,3,4,5,6,7,8,9$, 10 and 11 using $0.1 \mathrm{M} \mathrm{NaOH}$ and $\mathrm{HNO}_{3}$ solutions and was noted by a $\mathrm{pH}$ meter. The bottles were kept in a shaker and shaken for up to $4 \mathrm{~h}$ at $125 \mathrm{rpm}$ at $25^{\circ} \mathrm{C}$ under a controlled temperature. After shaking, the bottles were placed for $2 \mathrm{~h}$ and the final $\mathrm{pH}$ of each bottle was noted carefully. The value obtained for PZC of ZI-SAH was determined from eqn (2) and was found to be 7.2, as shown in Fig. 4b.

$$
\Delta \mathrm{pH}=\mathrm{pH}_{\mathrm{i}}-\mathrm{pH}_{\mathrm{f}}
$$

Here, $\mathrm{pH}_{\mathrm{i}}$ and $\mathrm{pH}_{\mathrm{f}}$ are the initial and final $\mathrm{pH}$ values of the solution, respectively.

\subsection{Effect of $\mathbf{p H}$ on $\%$ removal of dyes}

The removal ability of ZI-SAH was evaluated for both CR and CV in the entire $\mathrm{pH}$ range (3-11) under the same condition. The effect is illustrated in Fig. 5. From the data calculation and 

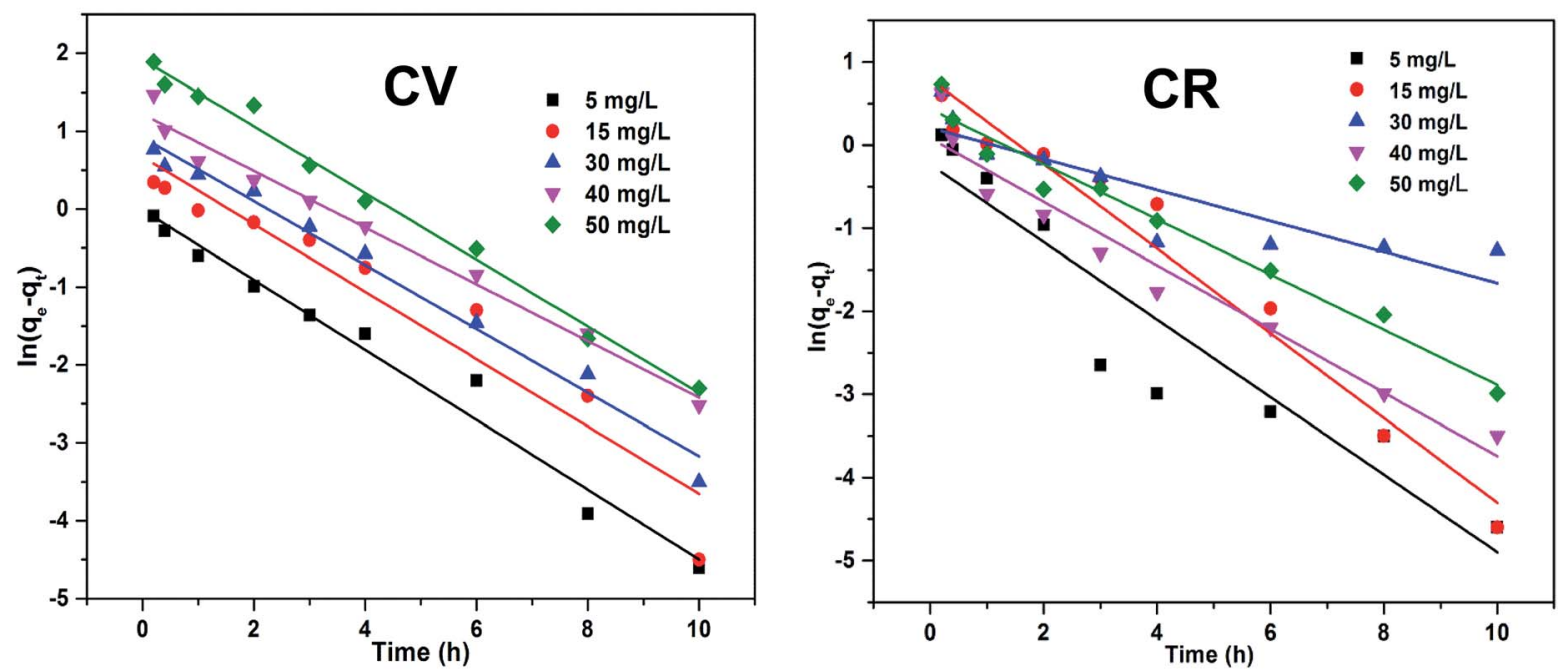

Fig. 13 Lagergren pseudo first-order kinetics of the adsorption of dyes (CV and CR) by ZI-SAH from aqueous media with different initial concentrations.

observation, it was found that the anionic dye (CR) was removed at $\mathrm{pH} 5$ (acidic medium), while the cationic dye (CV) was removed at $\mathrm{pH} 9$ although the anionic part of the $\mathrm{ZI}-\mathrm{SAH}$ system worked at all $\mathrm{pH}$ values. ${ }^{31}$ From the calculated data, it was found that the adsorption capacity of ZI-SAH increased from $50 \mathrm{mg} \mathrm{g}^{-1}$ to $57.5 \mathrm{mg} \mathrm{g}^{-1}$ (\% removal: 86.3) and then decreased to $54 \mathrm{mg}$ $\mathrm{g}^{-1}$ at $\mathrm{pH}$ 6. CV was removed at $\mathrm{pH} 9$ with a maximum adsorption capacity of $9.49 \mathrm{mg} \mathrm{g}^{-1}$ (\% removal: 97). The removal process was due to the diffusion and electrostatic attractions between the polymer network and dye molecules. As the ZI-SAH system possessed both charges at all $\mathrm{pH}$ values, high positive charge density was observed at $\mathrm{pH}<\mathrm{pH} \mathrm{PZC}$ and high negative charge density was observed at $\mathrm{pH}>\mathrm{pH}$ PZC. Therefore, the removal capability also varied and depended on the removal species. The removal efficiency of CR was high at low $\mathrm{pH}$ values because CR is a negatively charged macromolecule and the electrostatic interaction between CR and ZI-SAH (with high positive charge) was dominant. Similarly, ZI-SAH (with high negative charge) showed enhanced removal capability towards $\mathrm{CV}$ at high $\mathrm{pH}$ (optimum $\mathrm{pH}$ of 9) of the medium due to the positive charge on its structure. This property is very important and makes ZI-SAH more selective below and above the PZC value in any direction of the $\mathrm{pH}$ scale. The percent removal was calculated using eqn (3):

$$
\% \text { Removal }=\frac{\left(C_{\mathrm{o}}-C_{\mathrm{e}}\right)}{C_{\mathrm{o}}} \times 100
$$

Here, $C_{\mathrm{o}}$ is the initial concentration of dyes and $C_{\mathrm{e}}$ is the concentration of dyes at equilibrium.

\subsection{Contact time effect}

The effect of contact time was analyzed. We treated ZI-SAH (dose, $0.07 \mathrm{~g}$ ) for the removal of CV (at pH 9) and CR (at pH 5) by taking different initial concentrations $(5 \mathrm{ppm}, 15 \mathrm{ppm}$, $30 \mathrm{ppm}, 40 \mathrm{ppm}$ and $50 \mathrm{ppm}$ ) of dyes at $25^{\circ} \mathrm{C}$ in a temperature control shaker machine, while the contact time range was from $0.33 \mathrm{~h}$ (the first reading was taken at 20 minutes) to $14 \mathrm{~h}$ (equilibrium time). Initially, the rate of adsorption of both dyes was greater due to the availability of a large number of adsorption active sites in the hydrogel network. Gradually, the adsorption rate decreased due to the reduction in the number of active sites for adsorption till equilibrium was established. The

Table 3 Kinetic parameters measured for dye removal by $\mathrm{ZI}-\mathrm{SAH}$ in an aqueous medium

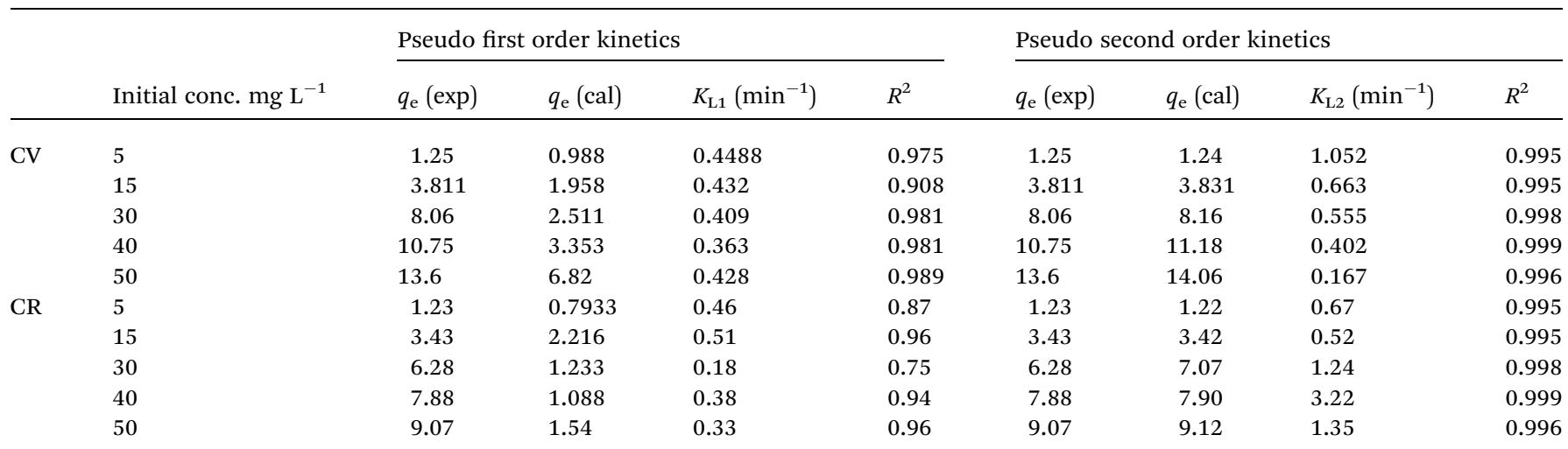



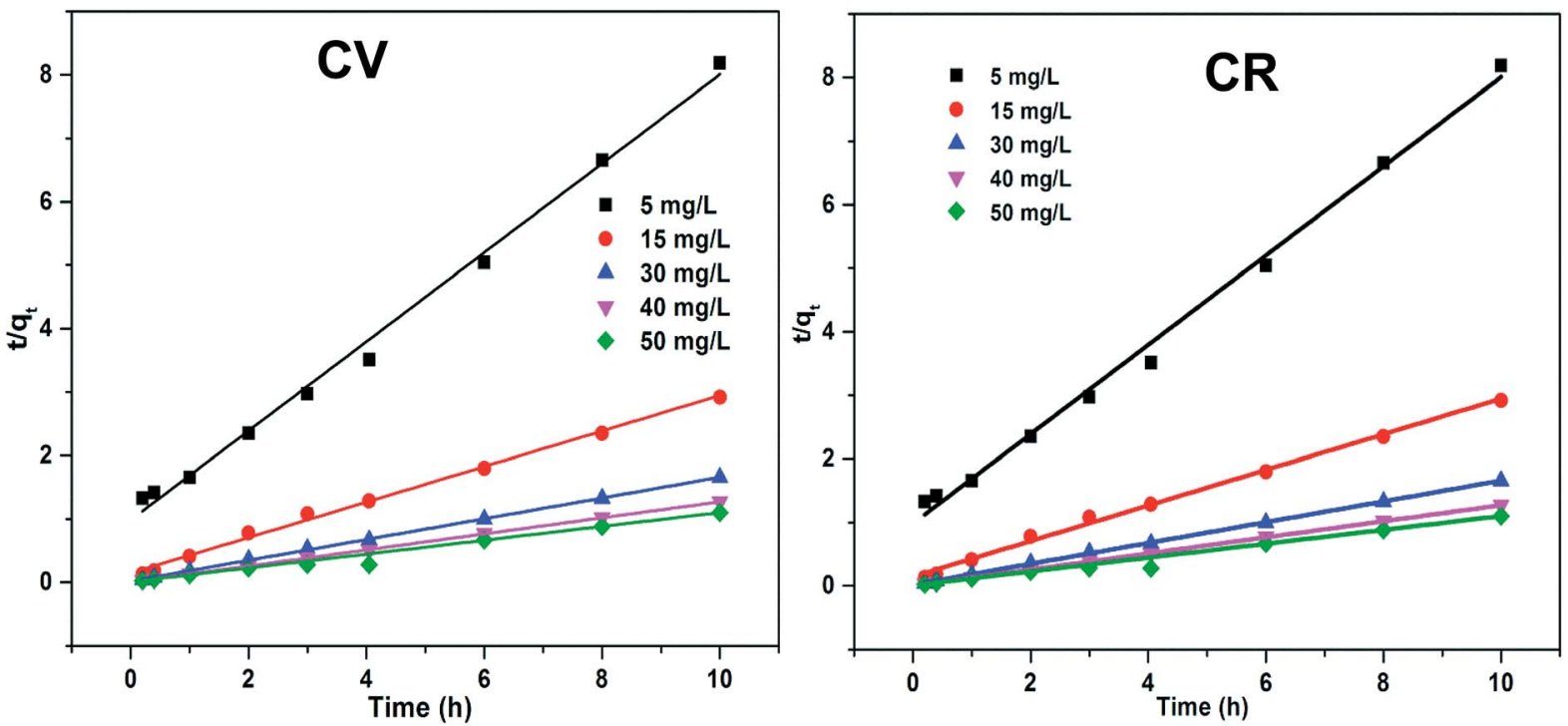

Fig. 14 Pseudo second order kinetics of the adsorption of dyes by ZI-SAH from an aqueous medium at different initial concentrations.

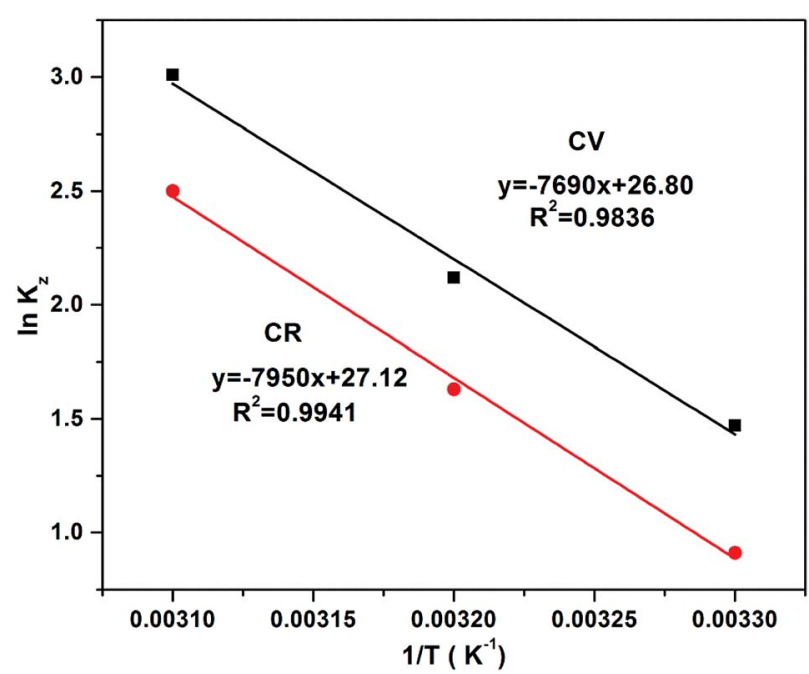

Fig. 15 Effects of temperature on absorption of $\mathrm{CV}$ and $\mathrm{CR}$ by $\mathrm{ZI}-\mathrm{SAH}$; dose $0.03 \mathrm{~g}, \mathrm{pH} 9$ for $\mathrm{CV}$ and $\mathrm{pH} 5$ for $\mathrm{CR}$ at temperatures of $303 \mathrm{~K}, 308$ $\mathrm{K}$ and $313 \mathrm{~K}$

data are plotted for $Q_{\mathrm{t}}$ (the amount in $\mathrm{mg}^{-1}$ adsorbed at time $\mathrm{t}$ ) vs. $t$ in Fig. 6, which indicates that the absorption rate is greater initially and gradually decreases with time. ${ }^{32}$ However, the equilibrium for CV was established earlier (Fig. 6a) compared to that for CR (Fig. 6b) although the equilibrium time for both was the same. The early establishment of equilibrium for CV as

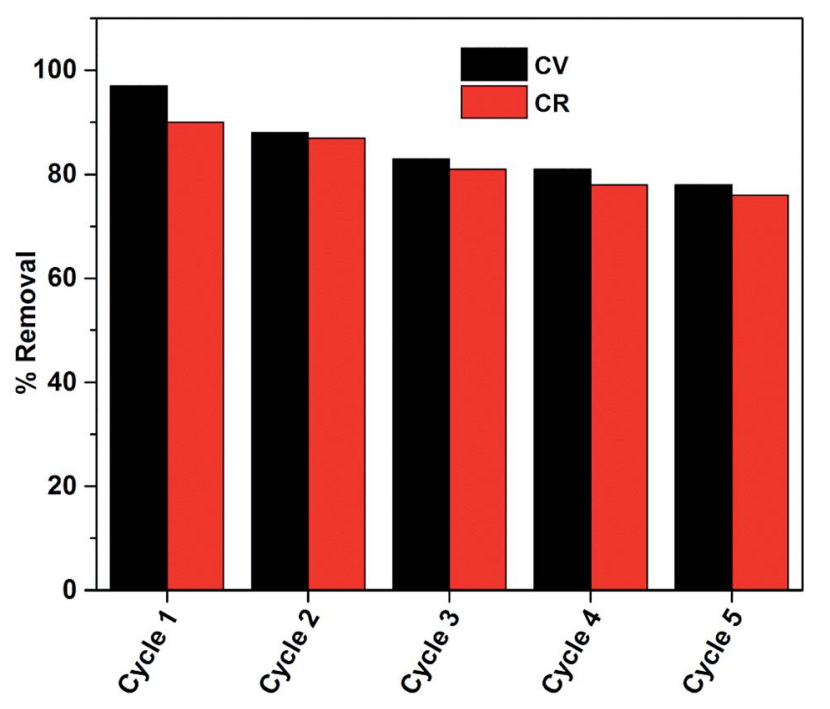

Fig. 16 Recycling and regeneration of $C V$ and $C R$.

compared to that for CR was because of the availability of a large number of active sites for $\mathrm{CV}$, which was based on the composition of the anionic monomers.

\subsection{Batch study of $\mathrm{CV}$ and $\mathrm{CR}$}

The absorption of CV and CR by ZI-SAH as an adsorbent was studied via batch experiments, maintaining the optimized $\mathrm{pH}$

Table 4 Various thermodynamic parameters for the adsorption of CV and CR at different temperatures

\begin{tabular}{|c|c|c|c|c|c|c|c|}
\hline \multirow[b]{2}{*}{ Dye } & \multirow[b]{2}{*}{ Initial conc. $\left(\mathrm{mg} \mathrm{L}^{-1}\right)$} & \multirow[b]{2}{*}{$\Delta S^{\circ}\left(\mathrm{J} \mathrm{mol}^{-1} \mathrm{~K}^{-1}\right)$} & \multirow[b]{2}{*}{$\Delta H^{\circ}\left(\mathrm{kJ} \mathrm{mol}^{-1}\right)$} & \multirow[b]{2}{*}{$R^{2}$} & \multicolumn{3}{|c|}{$\Delta G^{\circ}\left(\mathrm{kJ} \mathrm{mol}^{-1}\right)$} \\
\hline & & & & & $303 \mathrm{~K}$ & $308 \mathrm{~K}$ & $313 \mathrm{~K}$ \\
\hline $\mathrm{CV}$ & 10 & 0.23 & 63.93 & 0.983 & -3.639 & -4.754 & -5.869 \\
\hline CR & 15 & 0.22 & 66.09 & 0.9998 & -2.77 & -1.67 & -0.54 \\
\hline
\end{tabular}


for each pollutant for $14 \mathrm{~h}$. The maximum amount of dyes adsorbed $\left(q_{\mathrm{e}} \mathrm{mg} \mathrm{g}^{-1}\right)$ was calculated using eqn (4):

$$
q_{\mathrm{e}}=\frac{V\left(C_{\mathrm{o}}-C_{\mathrm{e}}\right)}{m}
$$

Here, $q_{\mathrm{e}}\left(\mathrm{mg} \mathrm{g}^{-1}\right)$ is the maximum amount of absorbed dyes in $\mathrm{mg} \mathrm{g}^{-1}$ on the ZI-SAH system, $C_{\mathrm{o}}$ is the initial equilibrium concentration in $\mathrm{mg} \mathrm{L}^{-1}$ of the dyes in liquid solution, $C_{\mathrm{e}}$ is the equilibrium concentration in $\mathrm{mg} \mathrm{L}^{-1}$ of the dyes in liquid solution, $m(\mathrm{~g})$ is the amount of ZI-SAH used as an adsorbent and $V$ is the volume (in $\mathrm{ml}$ ) of solution. The amounts of dyes removed with different initial concentrations are calculated and tabulated in Table 1. The data showed that the maximum adsorbed amount $q_{\mathrm{e}}\left(\mathrm{mg} \mathrm{g}^{-1}\right)$ of $\mathrm{CV}$ removed by the ZI-SAH system was greater than that of CR; however, the $q_{\mathrm{e}}\left(\mathrm{mg} \mathrm{g}^{-1}\right)$ values of both dyes increased with an increase in the initial concentration from $1.25 \mathrm{mg} \mathrm{g}^{-1}$ to $13.6 \mathrm{mg} \mathrm{g}^{-1}$ for $\mathrm{CV}$ and $1.23 \mathrm{mg} \mathrm{g}^{-1}$ to $9.07 \mathrm{mg} \mathrm{g}^{-1}$ for CR, as shown in Fig. 7b. Second, the $\%$ removal decreased with an increase in the initial concentration for both dyes, as shown in Fig. 7a. This was due to the availability of space in the polymer network. At low concentrations, the available space was large, while the same space became less for reactants used in high concentrations. Therefore, we reduced the \% removal capability of ZI-SAH, and the same results were reported previously by our group. ${ }^{9} \mathrm{~A}$ higher \% removal of $\mathrm{CV}$ at a higher initial concentration as compared to that for CR was due to the presence of high negative charge density on ZI-SAH as the amount of AAMPSA was higher in the ZI-SAH copolymer as compared to that of APTMACl.

\section{8. $\quad$ Effect of ZI-SAH dose}

The effect of the change in dosage for the removal of CV and CR was studied by considering different initial amounts of ZI-SAH ranging from 0.01 to $0.05 \mathrm{~g}$ at $\mathrm{pH} 9$ for $\mathrm{CV}$ and $\mathrm{pH} 5$ for $\mathrm{CR}$ at $25{ }^{\circ} \mathrm{C}$ for $14 \mathrm{~h}$ (equilibrium time). It was observed that the $\%$ removal of $\mathrm{CV}$ increased from 87 to $97.4 \%$ and for CR, it increased from 64 to $89 \%$ with an increase in the initial dose ranging from 0.01 to $0.05 \mathrm{~g}$, as shown in Fig. 8. This clearly indicated that with the increase in the amount of ZI-SAH, the availability of absorption space for dyes increased (in terms of functional groups), which ultimately favored more dye molecules to be entrapped inside the polymer network and increased their removal from the aqueous medium.

\subsection{Effect of ionic strength}

The effect of ionic strength was determined to investigate the absorption capability of ZI-SAH towards $\mathrm{CV}$ and CR using different concentrations of $\mathrm{KCl}$ and $\mathrm{NaNO}_{3}(0.1 \mathrm{M}, 0.2 \mathrm{M}, 0.3 \mathrm{M}$, $0.4 \mathrm{M}$ and $0.5 \mathrm{M}$ ). The results obtained are plotted in Fig. 9, which shows that the concentration of CV decreases with the increase in the concentrations of $\mathrm{KCl}$ and $\mathrm{NaNO}_{3}$. This was due to the increase in the number of $\mathrm{K}^{+}$ions and $\mathrm{Na}^{+}$ions in the solution, which blocked the active sites more in competition with the dye molecules, thus decreasing the $\mathrm{CV}$ absorption. ${ }^{33}$ However, it is clear from Fig. 9 (right) that the effect of $\mathrm{NaNO}_{3}$ compared to that of $\mathrm{KCl}$ on $\mathrm{CV}$ is more, which indicates that $\mathrm{Na}^{+}$ ions are strong competitors for CV molecules as compared to $\mathrm{K}^{+}$ ions. An opposite trend was observed for CR and its absorption capacity towards ZI-SAH increased with the incremental addition of $\mathrm{KCl}$ and $\mathrm{NaNO}_{3}$ (Fig. 9 (right)). The results show that the effect of $\mathrm{NaNO}_{3}$ remains greater in comparison to that of $\mathrm{KCl}$, which may be due to the common ion effect. When the $\mathrm{pH}$ of the solution is 9 , a greater number of $\mathrm{Na}^{+}$ions can be obtained from $\mathrm{NaOH}$ in the solution during $\mathrm{pH}$ adjustment. Furthermore, this phenomenon may be due to the presence of similar ions or co-ions in the solution, which can enhance the ionic strength of the entire medium due to the strong intermolecular forces, facilitating the entrapment of dye molecules in the ZISAH network. ${ }^{34,35}$

\subsection{Absorption isotherm models}

To study the mechanism of dye removal by ZI-SAH, different isotherms, i.e., Langmuir, Freundlich and Temkin were used. The study was performed at different temperatures, but the optimum temperature was selected where maximum absorption occurred.

3.10.1. Langmuir isotherm. The Langmuir model describes the mechanism of the adsorption of substances on the surface in a uniform manner, as presented in eqn (5). It is basically set on the concept of the homogenous monolayer formation of dyes on the surface of polymer gels.

$$
\frac{C_{\mathrm{e}}}{q_{\mathrm{e}}}=\frac{1}{q_{\mathrm{m}} K_{\mathrm{l}}}+\frac{C_{\mathrm{e}}}{q_{\mathrm{m}}}
$$

Here, $C_{\mathrm{e}}\left(\mathrm{mg} \mathrm{L}^{-1}\right)$ is the equilibrium concentration of dyes in solution, $q_{\mathrm{e}}\left(\mathrm{mg} \mathrm{g}^{-1}\right)$ is the maximum amount absorbed, $K_{\mathrm{l}}(\mathrm{L}$ $\mathrm{g}^{-1}$ ) represents the free energy known as the Langmuir constant and $q_{\mathrm{m}}\left(\mathrm{mg} \mathrm{g}^{-1}\right)$ is the maximum amount required for monolayer adsorption. The data were plotted as $C_{\mathrm{e}} / q_{\mathrm{e}} v s . C_{\mathrm{e}}$, as shown in Fig. 10; from the slope and intercept, $K_{\mathrm{l}}$ and $q_{\mathrm{m}}$ were calculated. The $K_{1}$ and $q_{\mathrm{m}}$ values for both $\mathrm{CV}$ and $\mathrm{CR}$ showed abnormality as the theoretical and experimental $q_{\mathrm{e}}\left(\mathrm{mg} \mathrm{g}^{-1}\right)$ values were not in a close correlation with the regression factor of 0.98 , as shown in Table 2. Thus, the adsorption is not chemical for both CV and CR. The feasibility of the adsorption process was further elaborated by measuring the equilibrium parameter or separation factor $\left(R_{\mathrm{L}}\right)$ using eqn (6) and the values are shown in Table 2.

$$
R_{\mathrm{L}}=\frac{1}{1+K_{\mathrm{l}} C_{\mathrm{o}}}
$$

Here, $C_{\mathrm{o}}$ is an initial concentration of dyes and $K_{\mathrm{l}}$ is the Langmuir constant. The $R_{\mathrm{L}}$ values for CR and $\mathrm{CV}$ in the present study were 0.218 and 0.122 , respectively, which indicated that the process of adsorption was favorable; however, the experimental and theoretical $q_{\mathrm{m}}\left(\mathrm{mg} \mathrm{g}^{-1}\right)$ values were not in a close relation to $\mathrm{CV}$ and CR but were not very far away from each other. Furthermore, the regression value (0.98) and the value of $\Delta H^{\circ}$ $\left(>40 \mathrm{~kJ} \mathrm{~mol}^{-1}\right.$ ) for both $\mathrm{CV}$ and CR dyes in our case were $63.93 \mathrm{~kJ} \mathrm{~mol}^{-1}$ and $66.09 \mathrm{~kJ} \mathrm{~mol}^{-1}$, respectively, which suggested the possibility of the Langmuir isotherms. Thus, the 
adsorption may be monolayer with an establishment of chemical bonds between the adsorbent and the adsorbate. ${ }^{36-38}$

3.10.2. Freundlich isotherm. The Freundlich model for adsorption mechanism is not restricted to monolayer homogeneity; thus, the Freundlich isotherm is an interpretation of the adsorption mechanism via the multilayer formation of heterogeneous surfaces. ${ }^{39}$ The logarithmic form of the Freundlich isotherm is represented in eqn (7):

$$
\log q_{\mathrm{e}}=\log K_{\mathrm{f}}+\frac{1}{n} \log C_{\mathrm{e}}
$$

Here, $q_{\mathrm{e}}\left(\mathrm{mg} \mathrm{g}^{-1}\right)$ is the maximum amount of dye absorbed, $C_{\mathrm{e}}$ $\left(\mathrm{mg} \mathrm{L}^{-1}\right)$ is the equilibrium concentration of dye in solution, $K_{\mathrm{f}}$ $\left(\mathrm{mg} \mathrm{g}^{-1}\right)$ is the adsorption capacity (known as the Freundlich adsorption constant), and $n$ is the Freundlich parameter, which is used to indicate the adsorption intensity. The graph is plotted for $\log q_{\mathrm{e}} v s$. $\log C_{\mathrm{e}}$ (Fig. 11); the parameters $K_{\mathrm{f}}$ and $n$ were determined from intercept and slope, respectively. The higher regression factor $\left(R^{2}\right)$ values, i.e., 0.9930 and 0.9837 for $\mathrm{CV}$ and $\mathrm{CR}$, respectively, compared with that for the Langmuir isotherm (Table 2) confirmed that the absorption of dyes by ZI-SAH follows both Langmuir and Freundlich isotherm models. However, the other parameter of the Freundlich model, namely, $n$ further highlighted the interface concentration within the solution, which can be justified by the $n$ values. In this study, the values of $n$ obtained for CV and CR were 1.60 and 1.32, respectively, which confirmed that the absorption of dyes by ZISAH is efficient. As the value of $n>1$, therefore the sorption process for CV and CR is corporative in this study. ${ }^{\mathbf{4 0}}$

3.10.3. Temkin isotherm. The Temkin isotherm model, as mentioned in eqn (8), gives information about the interaction of the adsorbate and absorbent. This model assumes that the heat of adsorption of all molecules in the layer can decrease linearly rather than logarithmically with coverage.

$$
q_{\mathrm{e}}=\frac{R T}{b_{\mathrm{T}}} \ln A_{\mathrm{T}}+\frac{R T}{b_{\mathrm{T}}} \ln C_{\mathrm{e}}
$$

Here, $b_{\mathrm{T}}$ is the Temkin constant related to the heat of adsorption, $T$ is the absolute temperature, $R$ is the universal gas constant (8.314 $\mathrm{J} \mathrm{K}^{-1} \mathrm{~mol}^{-1}$ ) and $A_{\mathrm{T}}$ is the isotherm equilibrium binding constant. Another constant $B=R T / b_{\mathrm{T}}$ can also be used, as shown in eqn (8). The data were plotted as $q_{\mathrm{e}}$ and $\ln C_{\mathrm{e}}$, as shown in Fig. 12. The $b_{\mathrm{T}}$ and $A_{\mathrm{T}}$ values were calculated from the slope and the intercept of the linear trend. The lower regression factor $\left(R^{2}\right)$ values of 0.83 and 0.94 for CV and CR, respectively, showed that the absorption of dyes by ZI-SAH does not follow the Temkin model (Table 2). Similarly, in the current study, the values of $A_{\mathrm{T}}$ (34.34 and $5.002 \mathrm{~L} \mathrm{~g}^{-1}$ for $\mathrm{CV}$ and $\mathrm{CR}$, respectively) and $B$ (157.10 and $1106.50 \mathrm{~J} \mathrm{~mol}^{-1}$ for $\mathrm{CV}$ and $\mathrm{CR}$, respectively) indicated a physical absorption process.

\subsection{Absorption kinetic study}

Two adsorption kinetic models, i.e., Lagergren pseudo first order and pseudo second order models were applied to investigate the kinetics and kinetic statistical parameters. The linear form of Lagergren pseudo first order kinetics is given in eqn (9):

$$
\ln \left(q_{\mathrm{e}}-q_{\mathrm{t}}\right)=\ln Q_{\mathrm{e}}-K_{\mathrm{L} 1} t
$$

Here, $q_{\mathrm{e}}\left(\mathrm{mg} \mathrm{g}^{-1}\right)$ is the maximum amount adsorbed at equilibrium, $q_{\mathrm{t}}\left(\mathrm{mg} \mathrm{g}^{-1}\right)$ is the amount adsorbed at various times $(t)$ before the establishment of equilibrium, and $K_{\mathrm{L} 1}\left(\mathrm{~min}^{-1}\right)$ is the constant called the rate constant of the pseudo first order kinetic equation.

The plot of $\ln \left(q_{\mathrm{e}}-q_{\mathrm{t}}\right)$ vs. $t$ is given in Fig. 13, where the kinetic parameters $Q_{\mathrm{e}}$ and $K_{\mathrm{L} 1}$ can be determined from the intercept and the slope of the plot, respectively, as tabulated in Table 3. The abnormal trend in $K_{\mathrm{L} 1}\left(\mathrm{~min}^{-1}\right)$ and low $R^{2}$ values indicated that the adsorption of $\mathrm{CV}$ and $\mathrm{CR}$ by ZI-SAH from an aqueous medium deviates from the pseudo first order kinetics. Furthermore, the $q_{\mathrm{e}}\left(\mathrm{mg} \mathrm{g}^{-1}\right)$ (calculated and experimental shown in Table 3) values for different initial concentrations did not have a close correlation with each other, which showed that the removal of $\mathrm{CV}$ and $\mathrm{CR}$ is not via pseudo first order kinetics.

Thus, the pseudo second order kinetic model was applied, the integrated form of which is given in eqn (10):

$$
\frac{t}{q_{\mathrm{t}}}=\frac{1}{K_{\mathrm{L} 2} q_{\mathrm{e}}}+\frac{t}{q_{\mathrm{e}}}
$$

Here, $K_{\mathrm{L} 2}\left(\mathrm{~min}^{-1}\right)$ is the rate constant of second order kinetics. In Fig. $14, t / q_{\mathrm{e}}$ is plotted against $t$; from the slope of the linear trend, the constant parameters can be measured, as given in Table 3 . The regression factor $\left(R^{2}\right)$ values for various concentrations of both CV and CR were greater than 0.98 or near to 1 , as shown in Table 3. This indicated that the absorption of dyes occurs through the mechanism of pseudo second order kinetics, which was further confirmed by the closeness of the calculated and experimental values of $q_{\mathrm{e}}\left(\mathrm{mg} \mathrm{g}^{-1}\right)$.

\subsection{Thermodynamic investigation}

Thermodynamic studies of the effects of various parameters on the absorption of $\mathrm{CV}$ and $\mathrm{CR}$ by ZI-SAH were performed by measuring $E_{\mathrm{a}}$ using the Arrhenius equation (eqn (11)), while $\Delta H^{\circ}, \Delta S^{\circ}$ and $\Delta G^{\circ}$ were calculated from eqn (12), (13) and (14), respectively:

$$
\begin{gathered}
\ln K_{\mathrm{z}}=\ln A-\frac{E_{\mathrm{a}}}{R T} \\
\Delta G^{\circ}=\Delta H^{\circ}-T \Delta S^{\circ} \\
\Delta G^{\circ}=-R T \ln K_{\mathrm{z}} \\
\ln K_{\mathrm{z}}=\frac{\Delta S^{\circ}}{R}-\frac{\Delta H^{\circ}}{R T}
\end{gathered}
$$

Here, $T$ is temperature in Kelvin, $R$ is the universal gas constant (8.314 $\mathrm{kJ} \mathrm{mol}^{-1} \mathrm{~K}^{-1}$ ) and $K_{\mathrm{z}}$ is the thermodynamic equilibrium constant; $\Delta S^{\circ}\left(\mathrm{J} \mathrm{mol}^{-1} \mathrm{~K}^{-1}\right), \Delta H^{\circ}\left(\mathrm{kJ} \mathrm{mol}^{-1}\right)$ and $\Delta G^{\circ}$ are the changes in entropy, enthalpy and Gibbs free energy, respectively. The data were plotted as $\ln K_{\mathrm{z}} v s .1 / T$, while the values of $\Delta S^{\circ}$ and $\Delta H^{\circ}$ were calculated from the intercept and slope of the plot, as shown in Fig. 15 and mentioned in Table 4. The obtained values of entropy and enthalpy were used in eqn (12) to obtain the value of Gibbs free energy to check the spontaneity of 
the process. The value of $K_{\mathrm{z}}$ was determined from the ratio of $C_{\text {ads }}$ (solid) (concentration of adsorption on solid) to $C_{\mathrm{e}}$ (liquid) (concentration in liquid at equilibrium).

The positive value of enthalpy showed that the absorption of $\mathrm{CV}$ and $\mathrm{CR}$ by ZI-SAH was endothermic in nature. The absorption was found to increase in value on increasing the temperature because the enthalpy value was positive, which showed the endothermic nature of the process. Thus, the increase in temperature favored the adsorption process and showed the affinity of CV and CR towards ZI-SAH. Similarly, the positive value of $\Delta S^{\circ}$ showed the increase in the disorder of dye molecules on the ZI-SAH system (randomness), while the negative value of free energy confirmed the spontaneity of the process. ${ }^{41}$

The spontaneity was studied at three different temperatures and the data were tabulated, as shown in Table 4. It was found that $\Delta G^{\circ}$ showed a negative value at all temperatures $(303,308$ and $313 \mathrm{~K}$ ), which confirmed the spontaneity and thermodynamic feasibility of removal at different temperatures. Furthermore, it was observed that the $\Delta G^{\circ}$ value shifted from -3.639 to $-5.869 \mathrm{~kJ} \mathrm{~mol}^{-1}$ in the case of $\mathrm{CV}$, which indicated that the $\mathrm{CV}$ removal by the increase in temperature (303 to 313 $\mathrm{K}$ ) is more spontaneous. However, the $\Delta \mathrm{G}^{\circ}$ value for CR changed from -2.77 to $-0.5 \mathrm{~kJ} \mathrm{~mol}^{-1}$, which showed that the adsorption of CR with the increase in temperature is less spontaneous.

\subsection{Regeneration and recycling of ZI-SAH}

ZI-SAH with entrapped dyes from the solution was regenerated by using $0.1 \mathrm{M} \mathrm{NaOH}$ solution. The entrapped dyes within ZI$\mathrm{SAH}$ were kept in $20 \mathrm{ml}$ of $0.1 \mathrm{M} \mathrm{NaOH}$ solution for $1 \mathrm{~h}$. It was found that the color (due to the presence of dye molecules) of ZI-SAH changed to colorless. The solution was also tested with $10 \mathrm{ml}$ acetone via the solvent extraction method, which washed away the dye molecules. For the regeneration and recycling of ZI-SAH, the second method was preferred. It was found that the regeneration of ZI-SAH was better and appropriate by acetone compared to that by $\mathrm{NaOH}$ because the addition of $\mathrm{NaOH}$ degraded the dyes within the hydrogels, while acetone extracted the dyes from the hydrogel network. Basically, $\mathrm{NaOH}$ reduced the chromophore of dyes and denatured it, as shown in the chemical reaction in Fig. $\mathrm{S} 1 . \dagger$ The color of crystal violet is because of the presence of the conjugated system of the three rings and $\mathrm{C}=\mathrm{C}$ bonds. However, when it reacts with the $\mathrm{OH}$ group, the $\mathrm{C}=\mathrm{C}$ bond is destroyed, due to which the conjugation becomes decentralized from $\mathrm{C}=\mathrm{C}$; hence, the chromophore and auxochrome become deactivated and thus, the substance (dye) becomes colorless. Congo red showed a similar behavior toward $\mathrm{NaOH}$ solution. ${ }^{42}$ The regenerated gels were further reused for the removal of dyes in 5 consecutive cycles and the \% removal was found to be greater than $75 \%$, which showed the good efficiency of ZI-SAH as compared to that of classical adsorbents. The classical adsorbents such as saw dust, peels of various fruits and vegetables, and nut shells require modification and functionalization before use and their recycling involves multiple steps, which overall limits the impact on these species (Fig. 16).

\section{Conclusion}

The zwitterionic superabsorbent hydrogel (ZI-SAH) system was synthesized through free radical polymerization at $60{ }^{\circ} \mathrm{C}$ for 30 minutes in an oven. The rheological study revealed that the behavior of the gels was non-Newtonian, pseudo-plastic and semi-solid in nature, which was a good indication for the use the gel in adsorption applications. ZI-SAH was successfully applied for the removal of crystal violet and congo red. The effects of various parameters such as contact time, $\mathrm{pH}$ and ionic strength were examined. The Langmuir, Freundlich and Temkin isotherm models were studied to elucidate the mechanism of the adsorption process of the dyes on ZI-SAH. It was found that both CV and CR followed the Freundlich adsorption model. The kinetic investigation showed that the removal of dyes followed pseudo second order kinetics. The stability of the ZI-SAH system was checked through regeneration and reuse for five consecutive cycles. The results indicated that ZI-SAH could be used after multiple cycles with $>75 \%$ removal efficiency. Easy synthesis (single-step one-pot synthesis), regeneration, and quick recycling with better efficiency in multiple cycles make ZISAH cost-effective and more suitable for dye removal from an aqueous medium compared to other classical adsorbents.

\section{Conflicts of interest}

There are no conflicts to declare.

\section{Acknowledgements}

The authors are very thankful to Higher Education Commission of Pakistan for financial support under Startup research grant program No. 21-718/SRGP/R\&D/HEC/2016 and National Research Program for Universities (NRPU) No. 7309.

\section{References}

1 C. R. Holkar, A. J. Jadhav, D. V. Pinjari, N. M. Mahamuni and A. B. Pandit, J. Environ. Manage., 2016, 182, 351-366.

2 K. Yamjala, M. S. Nainar and N. R. Ramisetti, Food Chem., 2016, 192, 813-824.

3 A. A. Prasada, G. Kumara and D. M. Thomas, Bulletin of Chemical and Pharma Research, 2017, 1, 30-39.

4 C. Gomes, J. Piccin and M. Gutterres, Process Saf. Environ. Prot., 2016, 99, 98-106.

5 M. Premkumar, K. Thiruvengadaravi, P. S. Kumar, J. Nandagopal and S. Sivanesan, in Environmental Contaminants, Springer, 2018, pp. 317-360.

6 C. Dong, J. Lu, B. Qiu, B. Shen, M. Xing and J. Zhang, Appl. Catal., B, 2018, 222, 146-156.

7 Y. Zhang, N. Klamerth, P. Chelme-Ayala and M. Gamal ElDin, Environ. Sci. Technol., 2016, 50, 10535-10544.

8 C. Wang, Y. Zhan and Z. Wang, ChemistrySelect, 2018, 3, 1713-1718.

9 R. Javed, L. A. Shah, M. Sayed and M. S. Khan, RSC Adv., 2018, 8, 14787-14797. 
10 R. Dubey, J. Bajpai and A. Bajpai, Journal of Water Process Engineering, 2015, 5, 83-94.

11 B. Shi, G. Li, D. Wang, C. Feng and H. Tang, J. Hazard. Mater., 2007, 143, 567-574.

12 X. Chen, G. Chen and P. L. Yue, Chem. Eng. Sci., 2003, 58, 995-1001.

13 J. Willkomm, K. L. Orchard, A. Reynal, E. Pastor, J. R. Durrant and E. Reisner, Chem. Soc. Rev., 2016, 45, 9-23.

14 J. Gu, H. Chen, F. Jiang and X. Wang, J. Colloid Interface Sci., 2019, 540, 97-106.

15 A. Mehdinia, H. Mehrabi and A. Jabbari, New J. Chem., 2019, 43, 5581-5591.

16 S. Ekici and G. Guntekin, Sep. Sci. Technol., 2018, 53, 17771790.

17 N. Wei, X. Zheng, H. Ou, P. Yu, Q. Li and S. Feng, New J. Chem., 2019, 43, 5603-5610.

18 L. Gan, S. Shang, E. Hu, C. W. M. Yuen and S.-x. Jiang, Appl. Surf. Sci., 2015, 357, 866-872.

19 L. A. Shah, M. Khan, R. Javed, M. Sayed, M. S. Khan, A. Khan and M. Ullah, J. Cleaner Prod., 2018, 201, 78-87.

20 N. Sahiner, S. Demirci, M. Sahiner, S. Yilmaz and H. AlLohedan, J. Environ. Manage., 2015, 152, 66-74.

21 Z. Tang, O. J. Luo, X. Li, M. Zheng, J. J. Zhu, P. Szalaj, P. Trzaskoma, A. Magalska, J. Wlodarczyk and B. Ruszczycki, Cell, 2015, 163, 1611-1627.

22 Y. Zheng and A. Wang, Eur. Polym. J., 2015, 72, 661-686.

23 U. P. Shinde, B. Yeon and B. Jeong, Prog. Polym. Sci., 2013, 38, 672-701.

24 L. A. Shah, J. Mol. Liq., 2019, 288, 111045.

25 M. M. Siddiqui, S. Rais-Bahrami, B. Turkbey, A. K. George, J. Rothwax, N. Shakir, C. Okoro, D. Raskolnikov, H. L. Parnes and W. M. Linehan, JAMA, 2015, 313, 390-397.
26 O. Ozay, S. Ekici, Y. Baran, N. Aktas and N. Sahiner, Water Res., 2009, 43, 4403-4411.

27 D. Caccavo, S. Cascone, G. Lamberti and A. Barba, Chem. Soc. Rev., 2018, 47, 2357-2373.

28 M. Johnson Jr and D. Segalman, J. Non-Newtonian Fluid Mech., 1977, 2, 255-270.

29 M. A. Malana, R. Zohra and M. S. Khan, Korea-Aust. Rheol. J., 2012, 24, 155-162.

30 L. A. Shah, R. Javed, A. Khan, I. Bibi, N. S. Khattak and S. Alam, Z. Phys. Chem., 2018, DOI: 10.1515/zpch-2018-1310.

31 E. Su and O. Okay, React. Funct. Polym., 2018, 123, 70-79.

32 F. Zhang, B. Ma, X. Jiang and Y. Ji, Powder Technol., 2016, 302, 207-214.

33 L. Fayoumi, M. Ezzedine, H. Akel and M. El Jamal, Port. Electrochim. Acta, 2012, 30, 121-133.

34 M. M. Ibrahim, J. Environ. Chem. Eng., 2018, 102848.

35 X. Peng, D. Huang, T. Odoom-Wubah, D. Fu, J. Huang and Q. Qin, J. Colloid Interface Sci., 2014, 430, 272-282.

36 M. Alkan, Ö. Demirbaş, S. Celikcapa and M. Doğan, J. Hazard. Mater., 2004, 116, 135-145.

37 K. Selim, F. El Hosiny, M. A. Khalek and I. Osama, Colloid Surf. Sci., 2017, 2, 47.

38 F. I. El-Hosiny, M. A. Abdel-Khalek, K. A. Selim and I. Osama, Physicochem. Probl. Miner. Process., 2018, 54, 321-333.

39 W. Ni, H. Chen, J. Su, Z. Sun, J. Wang and H. Wu, J. Am. Chem. Soc., 2010, 132, 4806-4814.

40 K. Fytianos, E. Voudrias and E. Kokkalis, Chemosphere, 2000, 40, 3-6.

$41 \mathrm{H}$. J. Kumari, P. Krishnamoorthy, T. Arumugam, S. Radhakrishnan and D. Vasudevan, Int. J. Biol. Macromol., 2017, 96, 324-333.

42 L. Yang, Y. Xiang, L. Chen, D. Zhang, C. Wu, S. Zhang, J. Wang and D. Tian, J. Mol. Liq., 2017, 231, 655-662. 